NBER WORKING PAPER SERIES

\title{
EFFECTIVE LABOR REGULATION AND MICROECONOMIC FLEXIBILITY
}

\author{
Ricardo J. Caballero \\ Kevin N. Cowan \\ Eduardo M.R.A. Engel \\ Alejandro Micco \\ Working Paper 10744 \\ http://www.nber.org/papers/w10744
}

\author{
NATIONAL BUREAU OF ECONOMIC RESEARCH \\ 1050 Massachusetts Avenue \\ Cambridge, MA 02138 \\ September 2004
}

We thank Joseph Altonji, John Haltiwanger, Michael Keane, Norman Loayza and participants at the LACEA 2003 conference for useful comments. Caballero thanks the NSF for financial support. The views expressed herein are those of the author(s) and not necessarily those of the National Bureau of Economic Research.

(O2004 by Ricardo J. Caballero, Kevin N. Cowan, Eduardo M.R.A. Engel, and Alejandro Micco. All rights reserved. Short sections of text, not to exceed two paragraphs, may be quoted without explicit permission provided that full credit, including $\odot$ notice, is given to the source. 
Effective Labor Regulation and Microeconomic Flexibility

Ricardo J. Caballero, Kevin N. Cowan, Eduardo M.R.A. Engel, and Alejandro Micco

NBER Working Paper No. 10744

September 2004

JEL No. E24, J23, J63, J64, K00

\section{ABSTRACT}

Microeconomic flexibility, by facilitating the process of creative-destruction, is at the core of economic growth in modern market economies. The main reason for why this process is not infinitely fast, is the presence of adjustment costs, some of them technological, other institutional. Chief among the latter is labor market regulation. While few economists would object to such a view, its empirical support is rather weak. In this paper we revisit this hypothesis and find strong evidence for it. We use a new sectoral panel for 60 countries and a methodology suitable for such a panel. We find that job security regulation clearly hampers the creative-destruction process, especially in countries where regulations are likely to be enforced. Moving from the 20th to the 80th percentile in job security, in countries with strong rule of law, cuts the annual speed of adjustment to shocks by a third while shaving off about one percent from annual productivity growth. The same movement has negligible effects in countries with weak rule of law.

Ricardo J. Caballero

Department of Economics

MIT

Room E52-252a

Cambridge, MA 02142-1347

and NBER

caball@mit.edu

Kevin N. Cowan

Inter-American Development Bank
Eduardo M.R.A. Engel

Department of Economics

Yale University

28 Hillhouse Avenue

New Haven, CT 06511

and NBER

eduardo.engel@yale.edu

Alejandro Micco

Inter-American Development Bank 


\section{Introduction}

Microeconomic flexibility, by facilitating the ongoing process of creative-destruction, is at the core of economic growth in modern market economies. This basic idea has been with economists for centuries, was brought to the fore by Schumpeter fifty years ago, and has recently been quantified in a wide variety of contexts. ${ }^{1}$ In US Manufacturing, for example, more than half of aggregate productivity growth can be directly linked to this process. ${ }^{2}$

The main obstacle faced by microeconomic flexibility is adjustment costs. Some of these costs are purely technological, others are institutional. Chief among the latter is labor market regulation, in particular job security provisions. The literature on the impact of labor market regulation on the many different economic, political and sociological variables associated to labor markets and their participants is extensive and contentious. However, the proposition that job security provisions reduce restructuring is a point of agreement.

Despite this consensus, the empirical evidence supporting the negative impact of labor market regulation on microeconomic flexibility has been scant at best. This is not too surprising, as the obstacles to empirical success are legions, including poor measurement of restructuring activity and labor market institutions variables, both within a country and more so across countries. In this paper we make a new attempt. We develop a methodology that allows us to bring together the extensive new data set on labor market regulation constructed by Djankov et al. (2003) with comparable cross-country cross-sectoral data on employment and output from the UNIDO (2002) data-set. We also emphasize the key distinction between effective and official labor market regulation.

The methodology builds on the simple partial-adjustment idea that larger adjustment costs are reflected in slower employment adjustment to shocks. ${ }^{3}$ The accumulation of limited adjustment to these shocks builds a wedge between frictionless and actual employment, which is the main right hand side variable in this approach. We propose a new way of estimating this wedge, which allows us to pool data on labor market legislation with comparable employment and output data for a broad range of countries. As a result, we are able to enlarge the effective sample to 60 economies, more than double the country coverage of previous studies in this literature. ${ }^{4}$ Our attempt to measure effective labor regulation interacts existing measures of job security provision with measures of rule of law and government efficiency.

Our results are clear and robust: countries with less effective job security legislation adjust more quickly to imbalances between frictionless and actual employment. In countries with strong rule of law, moving from the 20th to the 80th percentile of job security lowers the speed of adjustment to shocks by 35 percent and cuts annual productivity growth by 0.86 percent. The same movement for countries with low rule of law

\footnotetext{
${ }^{1}$ See, e.g., the review in Caballero and Hammour (2000).

${ }^{2}$ See, e.g., Foster, Haltiwanger and Krizan (1998).

${ }^{3}$ For surveys of the empirical literature on partial-adjustment see Nickell (1986) and Hammermesh (1993).

${ }^{4}$ To our knowledge, the broadest cross-country study to date - Nickell and Nuziata (2000) - included 20 high income OECD countries. Other recent studies, such as Burgess and Knetter (1998) and Burgess et al. (2000), pool industry-level data from 7 OECD economies.
} 
only reduces the speed of adjustment by approximately 1 percent and productivity growth by 0.02 percent.

The paper proceeds as follows. Section 2 presents the methodology and describes the new data set. Section 3 discusses the main results and explores their robustness. Section 4 gauges the impact of effective labor protection on productivity growth. Section 5 concludes.

\section{Methodology and Data}

\subsection{Methodology}

\subsubsection{Overview}

The starting point for our methodology is a simple adjustment hazard model, where the change in the number of (filled) jobs in sector $j$ in country $c$ between time $t-1$ and $t$ is a probabilistic (at least to the econometrician) function of the gap between desired and actual employment:

$$
\Delta e_{j c t}=\psi_{j c t} G_{a p} \quad G a p_{j c t} \equiv e_{j c t}^{*}-e_{j c, t-1}
$$

where $e_{j c t}$ and $e_{j c t}^{*}$ denote the logarithm of employment and desired employment, respectively. The random variable $\psi_{j c t}$, which is assumed i.i.d. both across sectors and over time, takes values in the interval $[0,1]$ and has country-specific mean $\lambda_{c}$ and variance $\omega_{c} \lambda_{c}\left(1-\lambda_{c}\right)$, with $0 \leq \omega_{c} \leq 1$. The case $\omega_{c}=0$ corresponds to the standard quadratic adjustment model, the case $\omega_{c}=1$ to the Calvo (1983) model. The parameter $\lambda_{c}$ captures microeconomic flexibility. As $\lambda_{c}$ goes to one, all gaps are closed quickly and microeconomic flexibility is maximum. As $\lambda_{c}$ decreases, microeconomic flexibility declines.

Equation (1) hints at two important components of our methodology: We need to find a measure of the employment gap and a strategy to estimate the average (over $j$ and $t$ ) speeds of adjustment (the $\lambda_{c}$ ). We describe both ingredients in detail in what follows. In a nutshell, we construct estimates of $e_{j c t}^{*}$, the only unobserved element of the gap, by solving the optimization problem of a sector's representative firm, as a function of observables such as labor productivity and a suitable proxy for the average market wage. We estimate $\lambda_{c}$ from (1), based upon the large cross-sectional size of our sample and the well documented heterogeneity in the realizations of the gaps and the $\psi_{j c t}$ 's (see, e.g., Caballero, Engel and Haltiwanger (1997) for US evidence).

\subsubsection{Details}

Output and demand for a sector's representative firm are given by:

$$
\begin{aligned}
y & =a+\alpha e+\beta h, \\
p & =d-\frac{1}{\eta} y,
\end{aligned}
$$


where $y, p, e, a, h, d$ denote output, price, employment, productivity, hours worked and demand shocks, and $\eta$ is the price elasticity of demand. We let $\gamma \equiv(\eta-1) / \eta$, with $\eta>1,0<\alpha<1,0<\beta<1$ and $\gamma<1 / \alpha$. All variables are in logs.

Firms are competitive in the labor market but pay wages that increase with the number of hours worked:

$$
w=k^{o}+\log \left(H^{\mu}+\Omega\right) .
$$

This can be approximated by:

$$
w=w^{o}+\mu(h-\bar{h}),
$$

with $w^{o}$ and $\mu$ determined by $k^{o}$ and $\Omega$, and $\bar{h}$ constant over time and interpreted below. In order to ensure interior solutions, we assume $\alpha \mu>\beta$ and $\mu>\beta \gamma$.

A key assumption is that the representative firm within each sector only faces adjustment costs when it changes employment levels, not when it changes the number of hours worked (beyond overtime payments). ${ }^{5}$ It follows that the sector's choice of hours in every period can be expressed in terms of its current level of employment, by solving the corresponding first order condition for hours.

In a frictionless labor market the firm's employment level also satisfies a simple static first order condition for employment. Our functional forms then imply that the optimal choice of hours, $\bar{h}$, does not depend on the employment level. A patient calculation shows that

$$
\bar{h}=\frac{1}{\mu} \log \left(\frac{\beta \Omega}{\alpha \mu-\beta}\right) .
$$

We denote the corresponding employment level by $\widehat{e}$ and refer to it as the static employment target:

$$
\widehat{e}=C+\frac{1}{1-\alpha \gamma}\left[d+\gamma a-w^{o}\right]
$$

with $C$ a constant that depends on $\mu, \alpha, \beta$ and $\gamma$.

The following relation between the employment gap and the hours gap then follows:

$$
\widehat{e}-e=\frac{\mu-\beta \gamma}{1-\alpha \gamma}(h-\bar{h})
$$

This is the expression used by Caballero and Engel (1993). It is not useful in our case, since we do not have information on worked hours. Yet the argument used to derive (5) also can be used to express the employment gap in terms of the marginal labor productivity gap:

$$
\widehat{e}-e=\frac{\phi}{1-\alpha \gamma}\left(v-w^{o}\right)
$$

where $v$ denotes marginal productivity, $\phi \equiv \mu /(\mu-\beta \gamma)$ is decreasing in the elasticity of the marginal wage

\footnotetext{
${ }^{5}$ For evidence on this see Sargent (1978) and Shapiro (1986).
} 
schedule with respect to average hours worked, $\mu-1$, and $w^{o}$ was defined in (4). Note that $\widehat{e}-e$ is the difference between the static target $\widehat{e}$ and realized employment, not the dynamic employment gap $e_{j c t}^{*}-e_{j c t}$ related to the term on the right hand side of (1). However, if we assume that $d+\gamma a-w^{o}$ follows a random walk (possibly with an exogenously time varying drift) — an assumption consistent with the data ${ }^{6}$ - we have that $e_{j c t}^{*}$ is equal to $\widehat{e}_{j c t}$ plus a constant $\delta_{c t}$. It follows that

$$
e_{j c t}^{*}-e_{j c t-1}=\frac{\phi}{1-\alpha \gamma_{j}}\left(v_{j c t}-w_{j c t}^{o}\right)+\Delta e_{j c t}+\delta_{c t},
$$

where we have allowed for sector-specific differences in $\gamma$. Note that both marginal product and wages are in nominal terms. However, since these expressions are in logs, their difference eliminates the aggregate price level component.

We estimate the marginal productivity of labor, $v_{j c t}$, using output per worker multiplied by an industrylevel labor share, assumed constant whithin income groups and over time.

Two natural candidates to proxy for $w_{j c t}^{o}$ are the average (across sectors within a country, at a given point in time) of either observed wages or observed marginal productivities. The former is consistent with a competitive labor market, the latter may be expected to be more robust in settings with long-term contracts and multiple forms of compensation, where the salary may not represent the actual marginal cost of labor. ${ }^{7}$ We performed estimations using both alternatives and found no discernible differences (see below). This suggests that statistical power comes mainly from the cross-section dimension, that is, from the well documented and large magnitude of sector-specific shocks. In what follows we report the more robust alternative and approximate $w^{o}$ by the average marginal productivity, which leads to:

$$
e_{j c t}^{*}-e_{j c t-1}=\frac{\phi}{1-\alpha \gamma_{j}}\left(v_{j c t}-v_{\cdot c t}\right)+\Delta e_{j c t}+\delta_{c t} \equiv \mathrm{Gap}_{j c t}+\delta_{c t}
$$

where $v_{\text {.ct }}$ denotes the average, over $j$, of $v_{j c t}$, and we use this convention for other variables as well. The expression above ignores systematic variations in labor productivity across sectors within a country, for example, because (unobserved) labor quality may differ systematically across sectors. The presence of such heterogeneity would tend to bias estimates of the speed of adjustment downward. To incorporate this possibility we subtract from $\left(v_{j c t}-v_{\cdot c t}\right)$ in (7) a moving average of relative sectoral productivity, $\widehat{\theta}_{j c t}$, where

$$
\widehat{\theta}_{j c t} \equiv \frac{1}{2}\left[\left(v_{j c t-1}-v_{\cdot c t-1}\right)+\left(v_{j c t-2}-v_{\cdot c t-2}\right)\right] .
$$

As a robustness check, for our main specifications we also computed $\widehat{\theta}_{j c t}$ using a three and four periods moving average, without significant changes in our results (more on this when we check robustness in

\footnotetext{
${ }^{6}$ Pooling all countries and sectors together, the first order autocorrelation of the measure of $\Delta e_{j c t}^{*}$ constructed below is -0.018 . Computing this correlation by country the mean value is 0.011 with a standard deviation of 0.179 .

${ }^{7}$ While we have assumed a simple competitive market for the base salary (salary for normal hours) within each sector, our procedure could easily accommodate other, more rent-sharing like, wage setting mechanisms (with a suitable reinterpretation of some parameters, but not $\lambda_{c}$ ).
} 
Section 3.2). The resulting expression for the estimated employment-gap is:

$$
e_{j c t}^{*}-e_{j c t-1}=\frac{\phi}{1-\alpha \gamma_{j}}\left(v_{j c t}-\widehat{\theta}_{j c t}-v_{\cdot c t}\right)+\Delta e_{j c t}+\delta_{c t} \equiv \operatorname{Gap}_{j c t}+\delta_{c t},
$$

where $\alpha \gamma_{j}$ is constructed using the sample median of the labor share for sector $\mathrm{j}$ across year and income groups.

Rearranging (8), we estimate $\phi$ from

$$
\Delta e_{j c t}=-\frac{\phi}{1-\alpha \gamma_{j}}\left(\Delta v_{j c t}-\Delta v_{\cdot c t}\right)+\kappa_{c t}+v_{i t}+\Delta e_{j c t}^{*} \equiv-\phi z_{j c t}+\kappa_{c t}+\varepsilon_{j c t},
$$

where $\mathrm{\kappa}$ is a country-year dummy, $\Delta e_{j c t}^{*}$ is the change in the desired level of employment and $z_{j c t} \equiv$ $\left(\Delta v_{j c t}-\Delta v_{\cdot c t}\right) /\left(1-\alpha \gamma_{j}\right)$. We assume that changes in sectoral labor composition are negligible between two consecutive years. In order to avoid the simultaneity bias present in this equation $\left(\Delta v\right.$ and $\Delta e^{*}$ are clearly correlated) we estimate (9) using $\left(\Delta w_{j c t-1}-\Delta w_{\cdot c t-1}\right)$ as an instrument for $\left(\Delta v_{j c t}-\Delta v \cdot c t\right){ }^{8}$ Table 1 reports the estimation results of (9) for the full sample of countries and across income groups. The first two columns use the full sample, with and without two percent of extreme values for the independent variable, respectively. The remaining columns report the estimation results for each of our three income groups and job security groups (more on both of these measures in Section 2.2). Based on our results for the baseline case, we set the value of $\phi$ at its full sample estimate of 0.4 for all countries in our sample.

It is important to point out that our methodology has some advantages over standard partial adjustment estimations. First, it summarizes in a single variable all shocks faced by a sector. This feature allows us to increase precision and to study the determinants of the speed of adjustment using interaction terms. Second, and related, it only requires data on nominal output and employment, two standard and well-measured variables in most industrial surveys. Most previous studies on adjustment costs required measures of real output or an exogenous measure of sector demand. ${ }^{9}$

\subsubsection{Regressions}

The central empirical question of the present study is how cross-country differences in job security regulation affect the speed of adjustment. Accordingly, from (1) and (8) it follows that the basic equation we estimate is:

$$
\Delta e_{j c t}=\lambda_{c t}\left(\operatorname{Gap}_{j c t}+\delta_{c t}\right)
$$

\footnotetext{
${ }^{8} \mathrm{We}$ lag the instrument to deal with the simultaneity problem and use the wage rather than productivity to reduce the (potential) impact of measurement error bias.

${ }^{9}$ Abraham and Houseman (1994), Hammermesh (1993), and Nickel and Nunziata (2000)) evaluate the differential response of employment to observed real output. A second option is to construct exogenous demand shocks. Although this approach overcomes the real output concerns, it requires constructing an adequate sectorial demand shock for every country. A case in point are the papers by Burgess and Knetter (1998) and Burgess et al. (2000), which use the real exchange rate as their demand shock. The estimated effects of the real exchange rate on employment are usually marginally significant, and often of the opposite sign than expected.
} 
where $\Delta e_{j c t}$ is the log change in employment and $\lambda_{c t}$ denotes the speed of adjustment. We assume that the latter takes the form:

$$
\lambda_{c t}=\lambda_{1}+\lambda_{2} \mathrm{JS}_{c t}^{\mathrm{eff}}
$$

where $\mathrm{JS}_{c t}^{\text {eff }}$ is a measure of effective job security regulation. In practice we observe job security regulation (imperfectly), but not the rigor with which it is enforced. We proxy the latter with a "rule of law" variable, so that

$$
\mathrm{JS}_{c t}^{\mathrm{eff}}=\mathrm{JS}_{c t}\left(1+a \mathrm{RL}_{c t}\right)
$$

where $a$ is a constant and $\mathrm{RL}_{c t}$ is a standard measure of rule of law (see below). Substituting this expression in (11) and the resulting expression for $\lambda_{c t}$ in (10), yields our main estimating equation:

$$
\Delta e_{j c t}=\lambda_{1} \operatorname{Gap}_{j c t}+\lambda_{2}\left(\operatorname{Gap}_{j c t} \times \mathrm{JS}_{c t}\right)+\lambda_{3}\left(\operatorname{Gap}_{j c t} \times \mathrm{JS}_{c t} \times \mathrm{RL}_{c t}\right)+\widetilde{\delta}_{c t}+\varepsilon_{j c t},
$$

with $\lambda_{3}=a \lambda_{2}$ and $\widetilde{\delta}_{c t}$ denotes country $\times$ time fixed effects (proportional to the $\delta_{c t}$ defined above).

The main coefficients of interest are $\lambda_{2}$ and $\lambda_{3}$, which measure how the speed of adjustment varies across countries depending on their labor market regulation (both de jure and de facto).

\subsection{The Data}

This section describes our sample and main variables. Additional variables are defined as we introduce them later in the text.

\subsubsection{Job Security and Rule of Law}

We use two measures of job security, or legal protection against dismissal: the job security index constructed by Djankov et al. (2003) for 60 countries world-wide (henceforth $\mathrm{JS}_{c}$ ) and the job security index constructed by Heckman and Pages (2000) for 24 countries in OECD and Latin America (henceforth $\mathrm{HP}_{c t}$ ). The $\mathrm{JS}_{c}$ measure is available for a larger sample of countries and includes a broader range of job security variables. The $\mathrm{HP}_{c t}$ measure has the advantage of having time variation.

Our main job security index, $\mathrm{JS}_{c}$, is the sum of four variables, measured in 1997, each of which takes on values between 0 and 1: $(i)$ grounds for dismissal protection $P G_{c}$, (ii) protection regarding dismissal procedures $P P_{c}$, (iii) notice and severance payments $P S_{c}$, and (iv) protection of employment in the constitution $P C_{c}$. The rules on grounds of dismissal range from allowing the employment relation to be terminated by either party at any time (employment at will) to allowing the termination of contracts only under a very narrow list of "fair" causes. Protective dismissal procedures require employers to obtain the authorization of third parties (such as unions and judges) before terminating the employment contract. The third variable, notice and severance payment, is the one closest to the $\mathrm{HP}_{c t}$ measure, and is the normalized sum of two components: mandatory severance payments after 20 years of employment (in months) and months of advance notice for dismissals after 20 years of employment $\left(N S_{t c}=b_{c t+20}+S P_{c t+20}, t=1997\right)$. The four 
components of $\mathrm{JS}_{c}$ described above increase with the level of job security.

The Heckman and Pages measure is narrower, including only those provisions that have a direct impact on the costs of dismissal. To quantify the effects of this legislation, they construct an index that computes the expected (at hiring) cost of a future dismissal. The index includes both the costs of advanced notice legislation and firing costs, and is measured in units of monthly wages.

Our estimations also adjust for the level of enforcement of labor legislation. We do this by including measures of rule of law $\mathrm{RL}_{c}$ and government efficiency $\mathrm{GE}_{c}$ from Kaufmann at al. (1999), and interact them with $\mathrm{JS}_{c}$ and $\mathrm{HP}_{c t} .{ }^{10}$ We expect labor market legislation to have a larger impact on adjustment costs in countries with a stronger rule of law (higher $\mathrm{RL}_{c}$ ) and more efficient governments (higher $\mathrm{GE}_{c}$ ).

The institutional variables as well as the countries in our sample and their corresponding income group are reported in Table 2. Table 3 reports the sample correlations between our main cross-country variables and summary statistics for each of these measures for three income groups (based on World Bank per capita income categories). ${ }^{11}$ As expected, the correlation between the two measures of job security is positive and significant. Differences can be explained mainly by the broader scope of the $\mathrm{JS}_{c t}$ index. Also as expected, rule of law and government efficiency increase with income levels. Note, however, that neither measure of job security is positively correlated with income per capita, since both $\mathrm{JS}_{c t}$ and $\mathrm{HP}_{c}$ are highest for middle income countries.

\subsubsection{Industrial Statistics}

Our output, employment and wage data come from the 2002 3-digit UNIDO Industrial Statistics Database. The UNIDO database contains data for the period 1963-2000 for the 28 manufacturing sectors that correspond to the 3 digit ISIC code (revision 2). Because our measures of job security and rule of law are time invariant and measured in recent years, however, we restrict our sample to the period 1980-2000. Data on output and labor compensation are in current US dollars (inflation is removed through time effects in our regressions). Throughout the paper our main dependent variable is $\Delta e_{j c t}$, the log change in total employment in sector $j$ of country $c$ in period $t$.

A large number of countries are included in the original dataset - however our sample is constrained by the cross-country availability of the independent variables measuring job security. In addition, we drop two percent of extreme employment changes in each of the three income groups. For our main specification the resulting sample includes 60 economies. Table 3 shows descriptive statistics for the dependent variable by income group.

\footnotetext{
${ }^{10}$ For rule of law and government efficiency we use the earliest value available in the Kaufmann et al. (1999) database: 1996, since this is closest to the Djankov et al. (2003) measure, which is for 1997.

${ }^{11}$ Income groups are: 1=High Income OECD, 2=High Income Non OECD and Upper Middle Income, 3=Lower Middle Income and Low Income.
} 


\section{Results}

This section presents our main result, showing that effective job security has a significant negative effect on the speed of adjustment of employment to shocks in the employment-gap. It also presents several robustness exercises.

\subsection{Main results}

Recall that our main estimating equation is:

$$
\Delta e_{j c t}=\lambda_{1} \operatorname{Gap}_{j c t}+\lambda_{2}\left(\operatorname{Gap}_{j c t} \times \mathrm{JS}_{c}\right)+\lambda_{3}\left(\operatorname{Gap}_{j c t} \times \mathrm{JS}_{c} \times \mathrm{RL}_{c}\right)+\widetilde{\delta}_{c t}+\varepsilon_{j c t} .
$$

Note that we have dropped time subscripts from $\mathrm{JS}_{c}$ and $\mathrm{RL}_{c}$ as we only use time invariant measures of rule of law and job security in our baseline estimation. Note also that in all specifications that include the $\left(\mathrm{Gap}_{i c t} \times \mathrm{JS}_{c t} \times \mathrm{RL}_{c}\right)$ interaction we also include the respective $\mathrm{Gap}_{i c t} \times \mathrm{RL}_{c}$ as a control variable.

We start by ignoring the effect of job security on the speed of adjustment, and set $\lambda_{2}$ and $\lambda_{3}$ equal to zero. This gives us an estimate of the average speed of adjustment and is reported in column 1 of Table 4. On average (across countries and periods) we find that $60 \%$ of the employment-gap is closed in each period. Furthermore, our measure of the employment-gap and country $\times$ year fixed effects explain $60 \%$ of the variance in log-employment growth.

The next three columns present our main results, which are repeated in columns 5 to 7 allowing for different $\lambda_{1}$ by sectors and country income level. ${ }^{12}$ Column 2 (and 5) presents our estimate of $\lambda_{2}$. This coefficient has the right sign and is significant at conventional confidence levels. Employment adjusts more slowly to shocks in the employment-gap in countries with higher levels of official job security.

Next, we allow for a distinction between effective and official job security. Results are reported in columns 3 and 4 (and, correspondingly, 6 and 7) for different rules-enforcement criteria. In columns 3 and 6 the distinction between effective and official job security is captured by the product of $\mathrm{JS}_{c}$ and $\mathrm{DSRL}_{c}$, where $\mathrm{DSRL}_{c}$ is a dummy variable for countries with strong rule of law $\left(\mathrm{RL}_{c} \geq \mathrm{RL}_{\text {Greece }}\right.$ - where Greece is the OECD country with the lowest RL score). The three panels in Figure 1 show the value of the job security index for countries in the high, medium and low income groups, respectively. Now $\lambda_{2}$ becomes insignificant, while $\lambda_{3}$ has the right sign and is highly significant. That is, the same change in $\mathrm{JS}_{c}$ will have a significantly larger (downward) effect on the speed of adjustment in countries with stricter enforcement of laws, as measured by our rule-of-law dummy. The effect of the estimated coefficients reported in column 3 is large. In countries with strong rule of law, moving from the 20th percentile of job security $(-0.19)$ to the 80th percentile $(0.23)$ reduces $\hat{\lambda}$ by 0.22 . The same change in job security legislation has a considerable smaller effect, 0.006, on the speed of adjustment in the group of economies with weak rule of law. Employment

\footnotetext{
${ }^{12}$ We allow for an interaction between Gap ${ }_{j c t}$ and 3 digit ISIC sector dummies (we also include sector fixed effects). We also control for the possibility that our results are driven by omitted variables, correlated with our measures of job security. For this, we include an additional interaction between $\mathrm{Gap}_{j c t}$ and three income-group dummies.
} 
adjusts more slowly to shocks in the employment-gap in countries with higher levels of effective job security.

Columns 4 and 7 address whether the negative coefficient on $\lambda_{3}$ is robust to other measures of legal enforcement. To do so we use an alternative variable from the Kaufmann et al. (1999) dataset - government effectiveness (GE) - and construct a dummy variable for high effectiveness countries $\left(\mathrm{GE}_{c} \geq \mathrm{GE}_{\mathrm{Greece}}\right)$. Clearly, the results are very close to those reported in columns 3 and 7. Job security legislation has a significant negative effect on the estimated speed of adjustment when governments are effective - a proxy for enforcement of existing labor regulation.

Finally, the last column in Table 4 uses an alternative measure of job security. We repeat our specification from column 7 (including sector and income dummies) using the Heckman-Pages (2000) measure of job security. The $\mathrm{HP}_{c t}$ data are only available for countries in the OECD and Latin America so our sample size is reduced by half, and most low income countries are dropped. The flip side is that this measure is time varying which potentially allows us to capture the effects of changes in the job security regulation. As reported in column 8 , we find a negative and significant effect of $\mathrm{HP}_{c t}$ on the speed of adjustment.

\subsection{Further robustness}

We continue our robustness exploration by assessing the impact of three broad econometric issues: alternative gap-measures, exclusion of potential (country) outliers, and misspecification due to endogeneity of the gap measure.

\subsubsection{Alternative gap-measures}

Table 4 suggests that conditional on our measure of the employment-gap, our main findings are robust: job security, when enforced, has a significant negative impact on the speed of adjustment to the employment-gap. Table 5 tests the robustness of this result to alternative measures of the employment-gap. Columns 1 and 2 relax the assumption of a $\phi$ common across all countries. They repeat our baseline specifications - columns 2 and 3 in Table 4- using the values of $\phi$ estimated per income-group reported in Table 1. In turn, columns 3 and 4 report the results of using values of $\phi$ estimated across countries grouped by level of job security. ${ }^{13}$ Next, columns 5 through 8 repeat our baseline specifications using a three and four period moving average to estimate $\widehat{\theta}_{j c t}$. The final two columns ( 9 and 10) use an alternative specification for $w_{j c t}^{o}$ based on average wages instead of average productivity (see equation 8) to build $\mathrm{Gap}_{j c t}$. In all of the specifications reported in Table 5, our results remain qualitatively the same as in Table 4.

\subsubsection{Exclusion of potential (country) outliers}

Table 6 reports estimates of $\lambda_{2}$ and $\lambda_{3}$ using the specification from column 3 in Table 4 but dropping one country from our sample at a time. In all cases the estimated coefficient on $\lambda_{3}$ is negative and significant at conventional confidence intervals.

\footnotetext{
${ }^{13}$ Countries are grouped into the upper, middle and lower thirds of job security.
} 
However, it is also apparent in this table that excluding either Hong Kong or Kenya makes a substantial difference in the point estimates. For this reason, we re-estimate our model from scratch (that is, from $\phi$ up) now excluding these two countries. In this case the value of $\phi$ rises from 0.40 to 0.42 . Qualitatively, however, the main results remain unchanged. Table 7 reports these results.

\subsubsection{Potential endogeneity of the gap measure}

One concern with our procedure is that the construction of the gap measure includes the change in employment. While this does not represent a problem under the null hypothesis of the model, any measurement error in employment and $\phi z_{j t}$ could introduce important biases. We address this issue with two procedures.

Before describing these procedures, we note that the standard solution of passing the $\Delta e$-component of the gap defined in (8) to the left hand side of the estimating equation (10) does not work in our context. Passing $\Delta e$ to the left suggests that the coefficient on the resulting gap will be equal to $\lambda /(1-\lambda)$. As shown in Appendix A, this holds only in the case of a partial adjustment model $(\omega=0$ in the notation of Section 2.1). By contrast, in the case of a Calvo-type adjustment $(\omega=1)$, the corresponding coefficient will, on average, be negative. ${ }^{14}$ More important, even small departures from a partial adjustment model (small values of $\omega$ ) introduce significant biases when estimating $\lambda$ using this approach.

Next we turn to the two procedures. The first procedure maintains our baseline specification, but instruments for the contemporaneous gap measure. Given that $\mathrm{Gap}_{j c t}=\phi z_{j t}+\Delta e_{j c t}$ can be rewritten as $\phi z_{j, t-1}+\Delta e_{j c t}^{*}$, a natural instrument is the lag of the ex-post gap, $\phi z_{j c, t-1}$. Unfortunately, the latter is not a valid instrument if it is computed with measurement error and this error is serially correlated. In our specification this could be the case because we use a moving average to construct the estimate of relative sectoral productivity, $\widehat{\boldsymbol{\theta}}_{j c t}$. To avoid this problem, we construct an alternative measure of the ex-post gap letting wage data play the role of productivity data when calculating the $v$ and $\theta$ terms on the right hand side of (8).

The second procedure re-writes the model in a standard dynamic panel formulation that removes the contemporaneous employment change from the right hand side: ${ }^{15}$

$$
\Delta \operatorname{Gap}_{j c t}=\left(1-\lambda_{c}\right) \Delta \mathrm{Gap}_{j c t-1}+\varepsilon_{j c t}
$$

Table 8 reports the values of the average $\lambda$ estimated with these two alternative, and much less precise, procedures. For comparison purposes, the first row reproduces the first column in Table 4. The second row shows the result for the IV procedure based on using lagged wages as instruments. Finally, Row 3 reports the estimate from the dynamic panel. It is apparent from the table that the estimates of average $\lambda$ are in the right ballpark, and hence we conclude that the bias due to a potentially endogenous gap is not significant.

\footnotetext{
${ }^{14}$ In the Calvo-case, for every observation either the (modified) gap or the change in employment is zero. The former happens when adjustment takes place, the latter when it does not. It follows that the covariance of $\Delta e$ and the (modified) gap will be equal to minus the product of the mean of both variables. Since these means have the same sign, the estimated coefficient will be negative. See Appendix A for a formal derivation.

${ }^{15}$ To estimate this equation we follow Anderson and Hsiao (1982) and use twice and three-times lagged values of $\Delta \mathrm{Gap} j$ jct instruments for the RHS variable. Similar results are obtained if we follow Arellano and Bond (1991).
} 


\section{Gauging the Costs of Effective Labor Protection}

By impairing worker movements from less to more productive units, effective labor protection reduces aggregate output and slows down economic growth. In this section we develop a simple framework to quantify this effect. Any such exercise requires strong assumptions and our approach is no exception. Nonetheless, our findings suggest that the costs of the microeconomic inflexibility caused by effective protection is large. In countries with strong rule of law, moving from the 20th to the 80th percentile of job security lowers annual productivity growth somewhere between 0.9 and 1.2 percent. The same movement for countries with low rule of law has a negligible impact on TFP.

Consider a continuum of establishments, indexed by $i$, that adjust labor in response to productivity shocks, while their share of the economy's capital remains fixed over time. Their production functions exhibit constant returns to (aggregate) capital, $K_{t}$, and decreasing returns to labor:

$$
Y_{i t}=B_{i t} K_{t} L_{i t}^{\alpha}
$$

where $B_{i t}$ denotes plant-level productivity and $0<\alpha<1$. The $B_{i t}$ 's follow geometric random walks, that can be decomposed into the product of a common and an idiosyncratic component:

$$
\Delta \log B_{i t} \equiv b_{i t}=v_{t}+v_{i t}^{I},
$$

where the $v_{t}$ are i.i.d. $\mathcal{N}\left(\mu_{A}, \sigma_{A}^{2}\right)$ and the $v_{i t}$ 's are i.i.d. (across productive units, over time and with respect to the aggregate shocks) $\mathcal{N}\left(0, \sigma_{I}^{2}\right)$. We set $\mu_{A}=0$, since we are interested in the interaction between rigidities and idiosyncratic shocks, not in Jensen-inequality-type effects associated with aggregate shocks.

The price-elasticity of demand is $\eta>1$. Aggregate labor is assumed constant and set equal to one. We define aggregate productivity, $A_{t}$, as:

$$
A_{t}=\int B_{i t} L_{i t}^{\alpha} d i
$$

so that aggregate output, $Y_{t} \equiv \int Y_{i t} d i$, satisfies

$$
Y_{t}=A_{t} K_{t}
$$

Units adjust with probability $\lambda_{c}$ in every period, independent of their history and of what other units do that period. ${ }^{16}$ The parameter that captures microeconomic flexibility is $\lambda_{c}$. Higher values of $\lambda_{c}$ are associated with a faster reallocation of workers in response to productivity shocks.

Standard calculations show that the growth rate of output, $g_{Y}$, satisfies:

$$
g_{Y}=s A-\delta,
$$

\footnotetext{
${ }^{16}$ More precisely, whether unit $i$ adjusts at time $t$ is determined by a Bernoulli random variable $\xi_{i t}$ with probability of success $\lambda_{c}$, where the $\xi_{i t}$ 's are independent across units and over time. This corresponds to the case $\omega=1$ in Section 2.1.
} 
where $s$ denotes the savings rate (assumed exogenous) and $\delta$ the depreciation rate for capital.

Now compare two economies that differ only in their degree of microeconomic flexibility, $\lambda_{c, 1}<\lambda_{c, 2}$. Tedious but straightforward calculations relegated to Appendix B show that:

$$
g_{Y, 2}-g_{Y, 1} \simeq\left(g_{Y, 1}+\delta\right)\left[\frac{1}{\lambda_{c, 1}}-\frac{1}{\lambda_{c, 2}}\right] \theta
$$

with

$$
\theta=\frac{\alpha \gamma(2-\alpha \gamma)}{2(1-\alpha \gamma)^{2}} \sigma^{2}
$$

$\gamma=(\eta-1) / \eta, \sigma^{2}=\sigma_{I}^{2}+\sigma_{A}^{2} \cdot{ }^{17}$

We choose parameters to apply (19) as follows: The mark-up is set at 20\% (so that $\gamma=5 / 6$ ), $g_{Y, 1}$ to the average rate of growth per worker in our sample for the $1980-1990$ period, $0.7 \%, \sigma=27 \%,{ }^{18} \alpha=2 / 3$, and $\delta=6 \%$.

Table 9 reports estimated speeds of adjustment across countries. Table 10 reports the average annual productivity costs of the deviation between each quintile and the bottom quintile in estimated speed of adjustment. These numbers are large. More important, they imply that moving from the 20th to the 80th percentile in job security, in countries with strong rule of law, reduces annual productivity growth by $0.86 \%$. The same change in job security legislation has a much smaller effect on TFP growth, $0.02 \%$, in the group of economies with weak rule of law.

We are fully aware of the many caveats that such ceteris-paribus comparison can raise, but the point of the table is to provide an alternative metric of the potential significance of observed levels of effective labor protection. Moreover, these numbers are roughly consistent with what we obtain when running a regression of productivity growth on the estimated $\lambda_{c}$ 's for all the economies in our sample from 1980 to 1990 (see Table 11 and Figure 2). Focusing on the results controlling for income groups (column 3), the coefficient on $\lambda_{c}$ is around 0.05 and significant at the 1 percent level. Combining these estimates with those in Column 3 of Table 4 implies that when moving from the 20th to the 80th percentile in job security, annual TFP growth falls by as much as $1.18 \%$ in countries with high rule of law. In contrast, a similar improvement in labor regulation in countries with low rule law reduces TFP growth by only $0.03 \%$.

\section{Concluding Remarks}

Many papers have shown that, in theory, job security regulation depresses firm level hiring and firing decisions. Job security provisions increase the cost of reducing employment and therefore lead to fewer dis-

${ }^{17}$ There also is a (static) jump in the level of aggregate productivity when $\lambda$ increases, given by:

$$
\frac{A_{2}-A_{1}}{A_{1}} \simeq\left[\frac{1}{\lambda_{1}}-\frac{1}{\lambda_{2}}\right] \theta
$$

See Appendix B for the proof.

${ }^{18}$ This is the average across the five countries considered in Caballero et al. (2004). 
missals when firms are faced with negative shocks. Conversely, when faced with a positive shock, the optimal employment response takes into account the fact that workers may have to be fired in the future, and the employment response is smaller. The overall effect is a reduction of the speed of adjustment to shocks.

However, conclusive empirical evidence on the effects of job security regulation has been elusive. One important reason for this deficit has been the lack of information on employment regulation for a sufficiently large number of economies that can be integrated to cross sectional data on employment outcomes. In this paper we have developed a simple empirical methodology that has allowed us to fill some of the empirical gap by exploiting: (a) the recent publication of two cross-country surveys on employment regulations (Heckman and Pages (2000) and Djankov et al. (2003)) and, (b) the homogeneous data on employment and production available in the UNIDO dataset. Another important reason for the lack of empirical success is differences in the degree of regulation enforcement across countries. We address this problem by interacting the measures of employment regulation with different proxies for law-enforcement.

Using a dynamic labor demand specification we estimate the effects of job security across a sample of 60 countries for the period from 1980 to 1998 . We consistently find a relatively lower speed of adjustment of employment in countries with high legal protection against dismissal, especially when such protection is likely to be enforced. 


\section{References}

[1] Abraham, K. and S. Houseman (1994). "Does Employment Protection Inhibit Labor Market Flexibility: Lessons From Germany, France and Belgium.” In: R.M. Blank, editor, Protection Versus Economic Flexibility: Is There A Tradeoff?. Chicago: University of Chicago Press.

[2] Anderson, T.W. and C. Hsiao (1982). "Formulation and Estimation of Dynamic Models Using Panel Data," Journal of Econometrics, 18, 67-82.

[3] Arellano, M. and S.R. Bond (1991). "Some Specification Tests for Panel Data: Montecarlo Evidence and an Application to Employment Equations," Review of Economic Studies, 58, 277-298.

[4] Barro, R.J. and J.W. Lee (1996). "International Measures of Schooling Years and Schooling Quality," American Economic Review, Papers and Proceedings, 86, 218-223.

[5] Burgess. S. and M. Knetter (1998). "An International Comparison of Eployment Adjustment to Exchange Rate Fluctuations." Review of International Economics. 6(1): 151-163.

[6] Burgess, S., M. Knetter and C. Michelacci (2000). "Employment and Output Adjustment in the OECD: A Disaggregated Analysis of the Role of Job Security Provisions." Economica 67: 419-435.

[7] Caballero R. and E. Engel (1993). "Microeconomic Adjustment Hazards and Aggregate Dynamics." Quarterly Journal of Economics. 108(2): 359-83.

[8] Caballero R., E. Engel, and J. Haltiwanger (1997), "Aggregate Employment Dynamics: Building from Microeconomic Evidence," American Economic Review 87(1), 115-137.

[9] Caballero R., E. Engel, and A. Micco (2004), “Microeconomic Flexibility in Latin America," NBER Working Paper No. 10398.

[10] Caballero, R. and M. Hammour (2000). "Creative Destruction and Development: Institutions, Crises, and Restructuring," Annual World Bank Conference on Development Economics 2000, 213-241.

[11] Calvo, G (1983). "Staggered Prices in a Utility Maximizing Framework." Journal of Monetary Economics. 12: 383-98.

[12] Djankov, S., R. La Porta, F. Lopez-de-Silanes, A. Shleifer and J. Botero (2003). "The Regulation of Labor.” NBER Working Paper No. 9756.

[13] Foster L., J. Haltiwanger and C.J. Krizan (1998). "Aggregate Productivity Growth: Lessons from Microeconomic Evidence,” NBER Working Papers No. 6803.

[14] Heckman, J. and C. Pages (2000). "The Cost of Job Security Regulation: Evidence from Latin American Labor Markets.” Inter-American Development Bank Working Paper 430. 
[15] Hamermesh, D. (1993). Labor Demand, Princeton: Princeton University Press.

[16] Kaufmann, D., A. Kraay and P. Zoido-Lobaton (1999). "Governance Matters”. World Bank Policy Research Department Working Paper No. 2196.

[17] Mankiw, G.N. (1995). “The Growth of Nations,” Brookings Papers on Economic Activity, 275-326.

[18] Nickell, S. (1986). "Dynamic Models of Labour Demand", in O. Ashenfelter and R. Layard (eds.) Handbook of Labor Economics, Elsevier.

[19] Nickell, S. and L. Nunziata (2000). "Employment Patterns in OECD Countries." Center for Economic Performance Dscussion Paper 448.

[20] Sargent, T. (1978). "Estimation of Dynamic Labor Demand under Rational Expectations," J. of Political Economy, 86, 1009-44.

[21] Shapiro, M.D. (1986). "The Dynamic Demand for Capital and Labor," Quarterly Journal of Economics, 101, 513-42.

[22] UNIDO (2002). Industrial Statistics Database 2002 (3-digit level of ISIC code (Revision 2)). 


\section{APPENDICES}

\section{A Endogeneity of the Gap Measure}

The model is the one described in Section 2.1. Ignoring country differences and fixing $t,{ }^{19}$ we have that

$$
\Delta e_{j}=\psi_{j} x_{j}
$$

where $x_{j} \equiv e_{j t}^{*}-e_{j, t-1}$ and the $\psi$ are i.i.d., independent of the $x_{i}$, with mean $\lambda$ and variance $\omega \lambda(1-\lambda)$, $0 \leq \omega \leq 1$. It follows from (20) that:

$$
\Delta e_{j}=\lambda x_{j}+u_{j}
$$

with $u_{j} \equiv\left(\psi_{j}-\lambda\right) x_{j}$ satisfying the properties of an error term in a standard regression setting. Thus, if we observe the $\Delta e_{j}$ and $x_{j}$ and estimate (21), we obtain an unbiased and consistent estimator for $\lambda .^{20}$

Removing $\Delta e$ from the gap measure is equivalent to replacing $x_{j}$ by $z_{j} \equiv x_{j}-\Delta e_{j}$ in (21). It is obvious that $z_{j}=0$ when $\psi=1$ and $\Delta e_{j}=0$ when $\psi_{j}=0$. Since the two values $\psi_{j}$ takes in the Calvo case $(\omega=1)$ are 0 and 1 , we have that when estimating the regression coefficient via OLS the covariance in the numerator will be equal to minus the product of the average of $\Delta e_{j}$ and the average of the $z_{j}$. Since both averages have the same sign, it follows that the regression coefficient will be negative (or zero if both averages are equal to zero).

Since we are considering sectoral data, the case $\omega=1$ may seem somewhat extreme. The following proposition shows that even for small departures from the partial adjustment case, the bias is likely to be significant.

Proposition 1 Consider the setting described above. Denote by $\hat{\beta}$ the OLS estimate of the cofficient $\beta$ in

$$
\Delta e_{j}=\text { const }+\beta z_{j}+\text { error }
$$

Denote by $\mu$ and $\sigma^{2}$ the (theoretical) mean and variance of the $x_{j}$ 's. Then:

$$
\operatorname{plim}_{N \rightarrow \infty} \hat{\beta}=\frac{(1-\omega) \sigma^{2}-\omega \mu^{2}}{[1-(1-\omega) \lambda] \sigma^{2}+\omega \lambda \mu^{2}} \lambda
$$

Proof From $\Delta e_{j}=\psi_{j} x_{j}$ and $z_{j}=\left(1-\psi_{j}\right) x_{j}$ it follows that:

$$
\operatorname{Cov}(\Delta e, z)=\frac{1}{N} \sum_{i} \psi_{i}\left(1-\psi_{i}\right) x_{i}^{2}-\left(\frac{1}{N} \sum_{i} \psi_{i} x_{i}\right)\left(\frac{1}{N} \sum_{i}\left(1-\psi_{i}\right) x_{i}\right),
$$

\footnotetext{
${ }^{19}$ The latter is justified by the fact that most of our identification comes from cross-sectional variation.

${ }^{20}$ This, in a nutshell, is the essence of the estimation procedure described in detail in Section 2 of the main text, with $x_{j}$ corresponding to the gap measure defined in (8).
} 
and

$$
\operatorname{Var}(z)=\frac{1}{N} \sum_{i}\left(1-\psi_{i}\right)^{2} x_{i}^{2}-\left[\frac{1}{N} \sum_{i}\left(1-\psi_{i}\right) x_{i}\right]^{2} .
$$

Taking expectations over the $\psi_{i}$, conditional on the $x_{i}$, and letting $N$ tend to infinity leads to:

$$
\mathrm{E}[\hat{\beta}]=\frac{\mathrm{E}[\psi(1-\psi)]\left(\sigma^{2}+\mu^{2}\right)-\lambda(1-\lambda) \mu^{2}}{\mathrm{E}\left[(1-\psi)^{2}\right]\left(\sigma^{2}+\mu^{2}\right)-(1-\lambda)^{2} \mu^{2}}
$$

The result now follows from the expression above and the fact that:

$$
\begin{aligned}
\mathrm{E}[\psi(1-\psi)] & =(1-\omega) \lambda(1-\lambda), \\
\mathrm{E}\left[(1-\psi)^{2}\right] & =[1-(1-\omega) \lambda](1-\lambda) .
\end{aligned}
$$

It follows that $\operatorname{plim}_{N \rightarrow \infty} \hat{\beta}$ is decreasing in $\omega$, varying from $\lambda /(1-\lambda)$ when $\omega=0$ to $-\lambda \mu^{2} /\left(\sigma^{2}+\lambda \mu^{2}\right)$ when $\omega=1$. It also follows that $\operatorname{plim}_{N \rightarrow \infty} \hat{\beta}$ is decreasing in $|\mu|$, so that:

$$
\operatorname{plim}_{N \rightarrow \infty} \hat{\beta} \leq \frac{(1-\omega) \lambda}{1-(1-\omega) \lambda} .
$$

\section{B Gauging the Costs}

In this appendix we derive (19). From (18) and (19) it follows that it suffices to show that under the assumptions in Section 4 we have:

$$
\frac{A_{2}-A_{1}}{A_{1}} \simeq\left[\frac{1}{\lambda_{1}}-\frac{1}{\lambda_{2}}\right] \theta
$$

where we have dropped the subindex $c$ from the $\lambda$ and

$$
\theta=\frac{\alpha \gamma(2-\alpha \gamma)}{2(1-\alpha \gamma)^{2}}\left(\sigma_{I}^{2}+\sigma_{A}^{2}\right)
$$

with $\gamma=(\eta-1) / \eta$.

The intuition is easier if we consider the following, equivalent, problem. The economy consists of a very large and fixed number of firms (no entry or exit). Production by firm $i$ during period $t$ is $Y_{i, t}=A_{i, t} L_{i, t}^{\alpha}{ }^{21}$ while (inverse) demand for good $i$ in period $t$ is $P_{i, t}=Y_{i, t}^{-1 / \eta}$, where $A_{i, t}$ denotes productivity shocks, assumed to follow a geometric random walk, so that

$$
\Delta \log A_{i, t} \equiv \Delta a_{i, t}=v_{t}^{A}+v_{i, t}^{I},
$$

\footnotetext{
${ }^{21}$ That is, we ignore hours in the production function.
} 
with $v_{t}^{A}$ i.i.d. $\mathcal{N}\left(0, \sigma_{A}^{2}\right)$ and $v_{i, t}^{I}$ i.i.d. $\mathcal{N}\left(0, \sigma_{I}^{2}\right)$. Hence $\Delta a_{i, t}$ follows a $\mathcal{N}\left(0, \sigma_{T}^{2}\right)$, with $\sigma_{T}^{2}=\sigma_{A}^{2}+\sigma_{I}^{2}$. We assume the wage remains constant throughout.

In what follows lower case letters denote the logarithm of upper case variables. Similarly, ${ }^{*}$-variables denote the frictionless counterpart of the non-starred variable.

Solving the firm's maximization problem in the absence of adjustment costs leads to:

$$
\Delta l_{i, t}^{*}=\frac{\gamma}{1-\alpha \gamma} \Delta a_{i, t}
$$

and hence

$$
\Delta y_{i, t}^{*}=\frac{1}{1-\alpha \gamma} \Delta a_{i, t} .
$$

Denote by $Y_{t}^{*}$ aggregate production in period $t$ if there were no frictions. It then follows from (26) that:

$$
Y_{i, t}^{*}=e^{\tau \Delta a_{i, t}} Y_{i, t-1}^{*},
$$

with $\tau \equiv 1 /(1-\alpha \gamma)$, Taking expectations (over $i$ for a particular realization of $v_{t}^{A}$ ) on both sides of (27) and noting that both terms being multiplied on the r.h.s. are, by assumption, independent (random walk), yields

$$
Y_{t}^{*}=e^{\tau v_{t}^{A}+\frac{1}{2} \tau^{2} \sigma_{I-1}^{2}} Y_{t-1}^{*}
$$

Averaging over all possible realizations of $v_{t}^{A}$ (these fluctuations are not the ones we are interested in for the calculation at hand) leads to

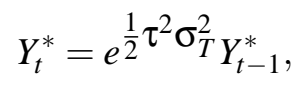

and therefore for $k=1,2,3, \ldots$ :

$$
Y_{t}^{*}=e^{\frac{1}{2} k \tau^{2} \sigma_{T}^{2}} Y_{t-k}^{*}
$$

Denote:

- $Y_{t, t-k}$ : aggregate $Y$ that would attain in period $t$ if firms had the frictionless optimal levels of labor corresponding to period $t-k$. This is the average $Y$ for units that last adjusted $k$ periods ago.

- $Y_{i, t, t-k}$ : the corresponding level of production of firm $i$ in $t$.

From the expressions derived above it follows that:

$$
\frac{Y_{i, t, t-1}}{Y_{i, t}^{*}}=\left(\frac{L_{i, t-1}^{*}}{L_{i, t}^{*}}\right)^{\alpha}=e^{-\alpha \gamma \tau \Delta a_{i, t}},
$$

and therefore

$$
Y_{i, t, t-1}=e^{\Delta a_{i, t}} Y_{i, t-1}^{*}
$$


Taking expectations (with respect to idiosyncratic and aggregate shocks) on both sides of the latter expression (here we use that $\Delta a_{i, t}$ is independent of $Y_{i, t-1}^{*}$ ) yields

$$
Y_{t, t-1}=e^{\frac{1}{2} \sigma_{T}^{2} Y_{t-1}^{*},}
$$

which combined with (29) leads to:

$$
Y_{t, t-1}=e^{\frac{1}{2}\left(1-\tau^{2}\right) \sigma_{T}^{2} Y_{t}^{*} .}
$$

A derivation similar to the one above, leads to:

$$
Y_{i, t, t-k}=e^{\Delta a_{i, t}+\Delta a_{i, t-1}+\ldots+\Delta a_{i, t-k+1}} Y_{t-k}^{*},
$$

which combined with (29) gives:

$$
Y_{t, t-k}=e^{-k \theta} Y_{t}^{*}
$$

with $\theta$ defined in (24).

Assuming Calvo-type adjustment with probability $\lambda$, we decompose aggregate production into the sum of the contributions of cohorts:

$$
Y_{t}=\lambda Y_{t}^{*}+\lambda(1-\lambda) Y_{t, t-1}+\lambda(1-\lambda)^{2} Y_{t, t-2}+\ldots
$$

Substituting (30) in the expression above yields:

$$
Y_{t}=\frac{\lambda}{1-(1-\lambda) e^{-\theta}} Y_{t}^{*}
$$

It follows that the production gap, defined as:

$$
\text { Prod. Gap } \equiv \frac{Y_{t}^{*}-Y_{t}}{Y_{t}^{*}}
$$

is equal to:

$$
\text { Prod. Gap }=\frac{(1-\lambda)\left(1-e^{-\theta}\right)}{1-(1-\lambda) e^{-\theta}} .
$$

A first-order Taylor expansion then shows that, when $|\theta|<<1$ :

$$
\text { Prod. Gap } \simeq \frac{(1-\lambda)}{\lambda} \theta \text {. }
$$

Subtracting this gap evaluated at $\lambda_{1}$ from its value evaluated at $\lambda_{2}$, and noting that this gap difference corresponds to $\left(A_{2}-A_{1}\right) / A_{1}$ in the main text, yields (23) and therefore concludes the proof. 
Figure 1: Job Security and Rule of Law in Countries with High, Medium and Low Income

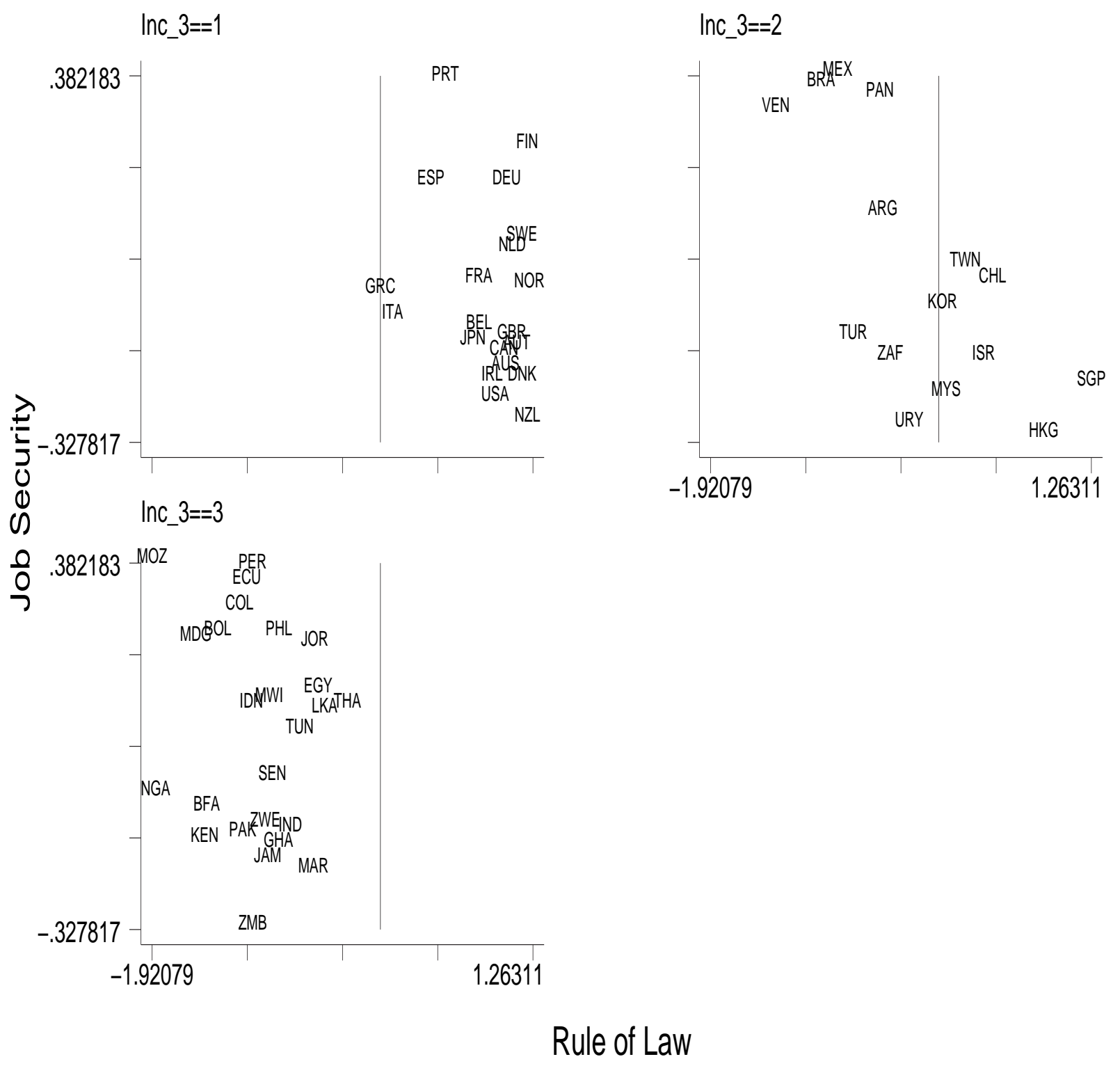


Figure 2: Productivity Growth and Speed of Adjustment coef $=.05275722, \mathrm{se}=.01829659, \mathrm{t}=2.88$

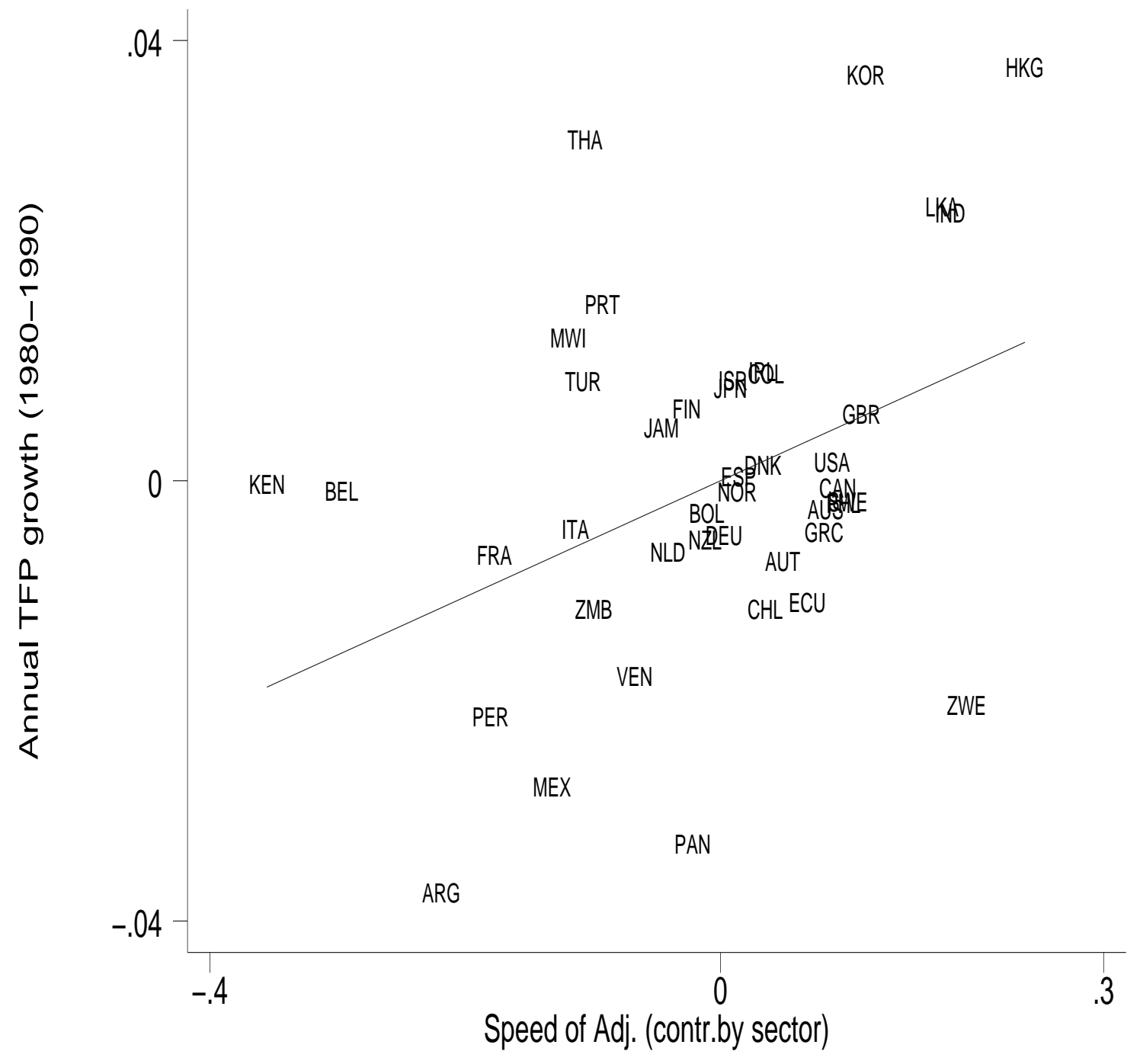


Table 1: Estimating $\phi$

\begin{tabular}{lcccccccc}
\hline \hline Specification: & $(1)$ & $(2)$ & $(3)$ & $(4)$ & $(5)$ & $(6)$ & $(7)$ & $(8)$ \\
\hline \multicolumn{7}{c}{} & \multicolumn{7}{c}{ Change in Employment (ln) } \\
$z_{j c t}$ & -0.280 & -0.394 & -0.558 & -0.355 & -0.387 & -0.363 & -1.168 & -0.352 \\
& $(0.044)$ & $(0.068)$ & $(0.135)$ & $(0.119)$ & $(0.116)$ & $(0.091)$ & $(.357)$ & $(0.103)$ \\
Observations & & & & & & & & \\
Income Group & 22,810 & 22,008 & 8,311 & 6,378 & 7,319 & 7,730 & 6,883 & 7,036 \\
Job Sec. Group & All & All & 1 & 2 & 3 & All & All & All \\
Extreme obs. of instrument & All & All & All & All & All & 1 & 2 & 3 \\
\hline
\end{tabular}

Standard errors reported in parentheses. All estimates are significant at the $1 \%$ level. All regressions use lagged $\Delta w_{i c t}-\Delta w_{\text {.ct }}$ as instrumental variable. As described in the main text, $z_{j c t}$ represents the log-change of the nominal marginal productivity of labor in each sector, minus the country average, divided by one minus the estimated labor share. All regressions includes a country-year fixed effect $\left(\kappa_{c t}\right.$ in $\left.(9)\right)$. Income groups are 1: High Income OECD, 2: High Income Non OECD and Upper Middle Income, and 3: Lower Middle Income and Low Income. Job Security Groups correspond to the highest, middle an lowest third of the measure in Djankov et al. (2003). 
Table 2: SAMPle Coverage And Main VARIAbleS

\begin{tabular}{|c|c|c|c|c|c|c|c|}
\hline \multirow[b]{2}{*}{ WDI code } & \multirow[b]{2}{*}{ Inc Group } & \multicolumn{2}{|c|}{ Job Security } & \multicolumn{4}{|c|}{ Institutions } \\
\hline & & Djankov et. al & $\mathrm{HP}$ & Strong RL & Rule of Law & Gov. Eff. & High Gov. Eff \\
\hline AUS & 1 & -0.19 & -0.71 & 1 & 1.03 & 0.95 & 1 \\
\hline AUT & 1 & -0.15 & -0.65 & 1 & 1.13 & 0.92 & 1 \\
\hline BEL & 1 & -0.11 & -0.70 & 1 & 0.81 & 0.81 & 1 \\
\hline CAN & 1 & -0.16 & -1.64 & 1 & 1.02 & 0.92 & 1 \\
\hline DEU & 1 & 0.17 & -1.56 & 1 & 1.04 & 0.92 & 1 \\
\hline DNK & 1 & -0.21 & & 1 & 1.17 & 1.02 & 1 \\
\hline ESP & 1 & 0.17 & 1.29 & 1 & 0.41 & 0.64 & 1 \\
\hline FIN & 1 & 0.24 & -0.82 & 1 & 1.22 & 0.89 & 1 \\
\hline FRA & 1 & -0.02 & -1.09 & 1 & 0.81 & 0.78 & 1 \\
\hline GBR & 1 & -0.13 & -1.00 & 1 & 1.09 & 1.05 & 1 \\
\hline GRC & 1 & -0.04 & -1.05 & 1 & -0.01 & -0.06 & 1 \\
\hline IRL & 1 & -0.21 & -1.40 & 1 & 0.92 & 0.82 & 1 \\
\hline ITA & 1 & -0.09 & 0.79 & 1 & 0.09 & 0.05 & 1 \\
\hline JPN & 1 & -0.14 & -1.84 & 1 & 0.76 & 0.46 & 1 \\
\hline NLD & 1 & 0.04 & -1.53 & 1 & 1.09 & 1.25 & 1 \\
\hline NOR & 1 & -0.03 & -1.55 & 1 & 1.23 & 1.13 & 1 \\
\hline NZL & 1 & -0.29 & -2.21 & 1 & 1.22 & 1.25 & 1 \\
\hline PRT & 1 & 0.37 & 2.05 & 1 & 0.53 & 0.24 & 1 \\
\hline SWE & 1 & 0.06 & -0.50 & 1 & 1.17 & 0.97 & 1 \\
\hline USA & 1 & -0.25 & -2.43 & 1 & 0.95 & 1.01 & 1 \\
\hline ARG & 2 & 0.11 & 0.56 & 0 & -0.48 & -0.37 & 0 \\
\hline BRA & 2 & 0.36 & 0.61 & 0 & -1.00 & -0.82 & 0 \\
\hline CHL & 2 & -0.02 & 0.21 & 1 & 0.44 & 0.32 & 1 \\
\hline HKG & 2 & -0.32 & & 1 & 0.86 & 0.81 & 1 \\
\hline ISR & 2 & -0.17 & & 1 & 0.36 & 0.42 & 1 \\
\hline KOR & 2 & -0.07 & 1.14 & 1 & 0.02 & -0.15 & 0 \\
\hline MEX & 2 & 0.38 & 0.73 & 0 & -0.86 & -0.85 & 0 \\
\hline MYS & 2 & -0.24 & & 1 & 0.05 & 0.18 & 1 \\
\hline PAN & 2 & 0.34 & 1.37 & 0 & -0.50 & -1.19 & 0 \\
\hline SGP & 2 & -0.22 & & 1 & 1.26 & 1.41 & 1 \\
\hline TUR & 2 & -0.13 & 1.54 & 0 & -0.73 & -0.69 & 0 \\
\hline TWN & 2 & 0.01 & & 1 & 0.21 & 0.49 & 1 \\
\hline URY & 2 & -0.30 & -0.20 & 0 & -0.26 & -0.17 & 0 \\
\hline VEN & 2 & 0.31 & 4.29 & 0 & -1.38 & -1.32 & 0 \\
\hline $\mathrm{ZAF}$ & 2 & -0.17 & & 0 & -0.42 & -0.40 & 0 \\
\hline BFA & 3 & -0.10 & & 0 & -1.46 & -1.38 & 0 \\
\hline BOL & 3 & 0.24 & 2.32 & 0 & -1.37 & -1.12 & 0 \\
\hline $\mathrm{COL}$ & 3 & 0.29 & 1.17 & 0 & -1.19 & -0.61 & 0 \\
\hline ECU & 3 & 0.34 & 0.97 & 0 & -1.13 & -1.29 & 0 \\
\hline EGY & 3 & 0.13 & & 0 & -0.53 & -0.99 & 0 \\
\hline GHA & 3 & -0.17 & & 0 & -0.86 & -0.78 & 0 \\
\hline IDN & 3 & 0.10 & & 0 & -1.09 & -0.55 & 0 \\
\hline IND & 3 & -0.14 & & 0 & -0.77 & -0.79 & 0 \\
\hline JAM & 3 & -0.20 & -0.44 & 0 & -0.95 & -1.06 & 0 \\
\hline JOR & 3 & 0.22 & & 0 & -0.56 & -0.54 & 0 \\
\hline KEN & 3 & -0.16 & & 0 & -1.48 & -1.13 & 0 \\
\hline LKA & 3 & 0.09 & & 0 & -0.48 & -0.93 & 0 \\
\hline MAR & 3 & -0.22 & & 0 & -0.57 & -0.73 & 0 \\
\hline MDG & 3 & 0.23 & & 0 & -1.55 & -1.39 & 0 \\
\hline MOZ & 3 & 0.38 & & 0 & -1.92 & -1.23 & 0 \\
\hline MWI & 3 & 0.11 & & 0 & -0.94 & -1.32 & 0 \\
\hline NGA & 3 & -0.07 & & 0 & -1.89 & -1.68 & 0 \\
\hline PAK & 3 & -0.15 & & 0 & -1.16 & -1.02 & 0 \\
\hline PER & 3 & 0.37 & 2.25 & 0 & -1.08 & -0.87 & 0 \\
\hline PHL & 3 & 0.24 & & 0 & -0.86 & -0.54 & 0 \\
\hline SEN & 3 & -0.04 & & 0 & -0.92 & -1.04 & 0 \\
\hline THA & 3 & 0.10 & & 0 & -0.29 & -0.32 & 0 \\
\hline TUN & 3 & 0.05 & & 0 & -0.69 & -0.24 & 0 \\
\hline ZMB & 3 & -0.33 & & 0 & -1.08 & -1.44 & 0 \\
\hline ZWE & 3 & -0.13 & & 0 & -0.97 & -0.86 & 0 \\
\hline
\end{tabular}


Table 3: Baseline SAmPle Statistics*

\begin{tabular}{|c|c|c|c|c|c|}
\hline \multicolumn{6}{|c|}{ Employment Growth (Yearly Avge.): 1980-2000 } \\
\hline Inc. Group & Obs. & Mean & SD & Min & Max \\
\hline 1 & 8,607 & -0.01 & 0.06 & -0.24 & 0.26 \\
\hline 2 & 6,063 & 0.00 & 0.11 & -0.43 & 0.42 \\
\hline 3 & 7,063 & 0.02 & 0.16 & -0.78 & 0.96 \\
\hline Total & 21,733 & 0.00 & 0.11 & -0.78 & 0.96 \\
\hline \multicolumn{6}{|c|}{ Job Security from Djankov et al. (2003): JS } \\
\hline Inc. Group & Countries & Mean & SD & Min & Max \\
\hline 1 & 20 & -0.05 & 0.18 & -0.29 & 0.37 \\
\hline 2 & 15 & -0.01 & 0.25 & -0.32 & 0.38 \\
\hline 3 & 25 & 0.05 & 0.21 & -0.33 & 0.38 \\
\hline Total & 60 & 0.00 & 0.21 & -0.33 & 0.38 \\
\hline
\end{tabular}

Job Security from Heckman and Pages (2001): HP

\begin{tabular}{ccrrrr}
\hline Inc. Group & Countries & Mean & SD & Min & Max \\
1 & 19 & -0.87 & 1.15 & -2.43 & 2.05 \\
2 & 9 & 1.14 & 1.30 & -0.20 & 4.29 \\
3 & 5 & 1.26 & 1.13 & -0.44 & 2.32 \\
Total & 33 & 0.00 & 1.54 & -2.43 & 4.29 \\
\hline \hline \multicolumn{6}{c}{ Rule of Law from Kaufmann et al. (1999): RL } \\
\hline Inc. Group & Countries & Mean & SD & Min & Max \\
1 & 20 & 0.88 & 0.37 & -0.01 & 1.23 \\
2 & 15 & -0.16 & 0.72 & -1.38 & 1.26 \\
3 & 25 & -1.03 & 0.42 & -1.92 & -0.29 \\
Total & 60 & -0.18 & 0.96 & -1.92 & 1.26 \\
\hline \hline
\end{tabular}

\begin{tabular}{ccrrrr}
\hline \multicolumn{6}{c}{ Government Effectiveness from Kaufmann et al. (1999): GE } \\
\hline Inc. Group & Countries & Mean & SD & Min & Max \\
1 & 20 & 0.80 & 0.37 & -0.06 & 1.25 \\
2 & 15 & -0.16 & 0.76 & -1.32 & 1.41 \\
3 & 25 & -0.95 & 0.36 & -1.68 & -0.24 \\
Total & 60 & -0.17 & 0.90 & -1.68 & 1.41 \\
\hline \hline \multicolumn{6}{c}{} \\
\hline \multicolumn{6}{c}{ Correlation Country Means } \\
\\
& 1.00 & HP & RL & GE \\
& JP & 0.66 & 1.00 & & \\
& RL & -0.36 & -0.77 & 1.00 & \\
& GE & -0.35 & -0.77 & 0.97 & 1.00 \\
\hline \hline
\end{tabular}

*Income groups are: 1=High Income OECD, 2=High Income Non OECD and Upper Middle Income, 3=Lower Middle Income and Low Income. 
Table 4: Estimation Results

\begin{tabular}{|c|c|c|c|c|c|c|c|c|}
\hline & (1) & (2) & (3) & $(4)$ & (5) & (6) & (7) & (8) \\
\hline & \multicolumn{8}{|c|}{ Change in Log-Employment } \\
\hline $\operatorname{Gap}\left(\lambda_{1}\right)$ & $\begin{array}{c}0.600 \\
(0.009)^{* * *}\end{array}$ & $\begin{array}{c}0.603 \\
(0.008)^{* * *}\end{array}$ & $\begin{array}{c}0.607 \\
(0.012)^{* * *}\end{array}$ & $\begin{array}{c}0.611 \\
(0.012)^{* * *}\end{array}$ & & & & \\
\hline $\operatorname{Gap} \times \operatorname{JS}\left(\lambda_{2}\right)$ & & $\begin{array}{c}-0.080 \\
(0.037)^{* *}\end{array}$ & $\begin{array}{l}-0.015 \\
(0.051)\end{array}$ & $\begin{array}{l}-0.025 \\
(0.051)\end{array}$ & $\begin{array}{c}-0.126 \\
(0.041)^{* * *}\end{array}$ & $\begin{array}{l}-0.027 \\
(0.052)\end{array}$ & $\begin{array}{l}-0.038 \\
(0.051)\end{array}$ & \\
\hline $\operatorname{Gap} \times \mathrm{JS} \times \operatorname{DSRL}\left(\lambda_{3}\right)$ & & & $\begin{array}{c}-0.514 \\
(0.068)^{* * *}\end{array}$ & & & $\begin{array}{c}-0.314 \\
(0.070)^{* * *}\end{array}$ & & \\
\hline $\operatorname{Gap} \times \operatorname{JS} \times \operatorname{DHGE}\left(\lambda_{3}\right)$ & & & & $\begin{array}{c}-0.515 \\
(0.068)^{* * *}\end{array}$ & & & $\begin{array}{c}-0.326 \\
(0.071)^{* * *}\end{array}$ & \\
\hline $\operatorname{Gap} \times \operatorname{HP}\left(\lambda_{2}\right)$ & & & & & & & & $\begin{array}{c}-0.022 \\
(0.007)^{* * * *}\end{array}$ \\
\hline \multicolumn{9}{|l|}{ Controls } \\
\hline Gap $\times$ Dummy High RL & & & $\begin{array}{c}-0.076 \\
(0.015)^{* * * *}\end{array}$ & & & $\begin{array}{c}0.086 \\
(0.023)^{* * *}\end{array}$ & & \\
\hline Gap $\times$ Dummy High GE & & & & $\begin{array}{c}-0.091 \\
(0.015)^{* * *}\end{array}$ & & & $\begin{array}{c}0.045 \\
(0.023)^{*}\end{array}$ & \\
\hline Observations & 21,733 & 21,733 & 21,733 & 21,733 & 21,733 & 21,733 & 21,733 & 12,012 \\
\hline R-squared & 0.60 & 0.60 & 0.60 & 0.60 & 0.61 & 0.61 & 0.61 & 0.62 \\
\hline Gap-Income Interaction & No & No & No & No & Yes & Yes & Yes & Yes \\
\hline Gap-Sector Interaction & No & No & No & No & Yes & Yes & Yes & Yes \\
\hline
\end{tabular}

* significant at $10 \%$; ** significant at 5\%; *** significant at $1 \%$. Robust standard errors in parentheses. JS and HP stand for the Djankov et al. (2003) and Heckman and Pages (2000) job security measures, respectively. DSRL and DHGE stand for strong Rule of Law and high Government Efficiency dummies (in both cases the threshold is given by Greece, see the main text), respectively, using the Kaufmann et al. (1999) indices. Each regression has country-year fixed effects. Gaps are estimated using a constant $\phi=0.40$. Sample excludes the upper and lower $1 \%$ of $\Delta e$ and of the estimated values of Gap. 


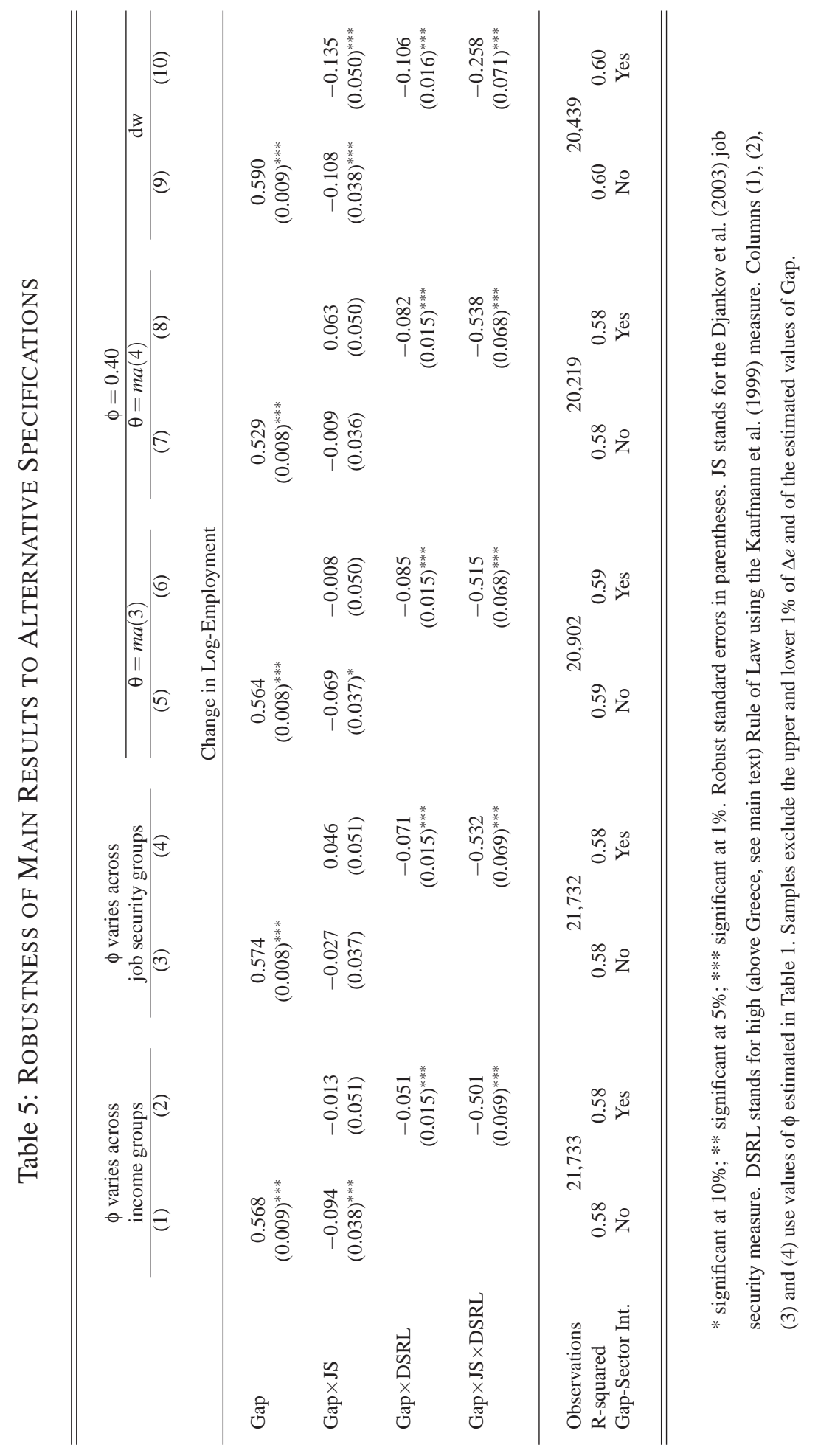


Table 6: Excluding One Country AT A Time

\begin{tabular}{|c|c|c|c|c|c|c|c|c|c|}
\hline \multirow[b]{2}{*}{ Country } & \multicolumn{2}{|c|}{$\lambda_{2}$} & \multicolumn{2}{|c|}{$\lambda_{3}$} & \multirow[b]{2}{*}{ Country } & \multicolumn{2}{|c|}{$\lambda_{2}$} & \multicolumn{2}{|c|}{$\lambda_{3}$} \\
\hline & Coeff. & St. Dev. & Coeff. & St. Dev. & & Coeff. & St. Dev. & Coeff. & St. Dev. \\
\hline ARG & -0.01 & 0.05 & -0.51 & 0.07 & KOR & -0.02 & 0.05 & -0.52 & 0.07 \\
\hline AUS & -0.02 & 0.05 & -0.52 & 0.07 & LKA & -0.02 & 0.05 & -0.51 & 0.07 \\
\hline AUT & -0.02 & 0.05 & -0.52 & 0.07 & MAR & -0.02 & 0.05 & -0.51 & 0.07 \\
\hline BEL & -0.02 & 0.05 & -0.52 & 0.07 & MDG & -0.02 & 0.05 & -0.51 & 0.07 \\
\hline BFA & -0.03 & 0.05 & -0.50 & 0.07 & MEX & 0.00 & 0.05 & -0.53 & 0.07 \\
\hline BOL & 0.00 & 0.05 & -0.52 & 0.07 & MOZ & 0.02 & 0.05 & -0.55 & 0.07 \\
\hline BRA & -0.01 & 0.05 & -0.52 & 0.07 & MWI & -0.01 & 0.05 & -0.52 & 0.07 \\
\hline CAN & -0.02 & 0.05 & -0.52 & 0.07 & NYS & -0.02 & 0.05 & -0.46 & 0.07 \\
\hline CHL & -0.02 & 0.05 & -0.53 & 0.07 & NGA & 0.00 & 0.05 & -0.53 & 0.07 \\
\hline COL & -0.02 & 0.05 & -0.51 & 0.07 & NLD & -0.02 & 0.05 & -0.51 & 0.07 \\
\hline DEU & -0.02 & 0.05 & -0.52 & 0.07 & NOR & -0.02 & 0.05 & -0.51 & 0.07 \\
\hline DNK & -0.02 & 0.05 & -0.52 & 0.07 & NZL & -0.02 & 0.05 & -0.53 & 0.07 \\
\hline ECU & -0.03 & 0.05 & -0.50 & 0.07 & PAK & 0.02 & 0.05 & -0.55 & 0.07 \\
\hline EGY & -0.02 & 0.05 & -0.51 & 0.07 & PAN & -0.01 & 0.05 & -0.52 & 0.07 \\
\hline ESP & -0.02 & 0.05 & -0.53 & 0.07 & PER & 0.06 & 0.05 & -0.59 & 0.07 \\
\hline FIN & -0.02 & 0.05 & -0.54 & 0.07 & PHL & -0.03 & 0.05 & -0.50 & 0.07 \\
\hline FRA & -0.02 & 0.05 & -0.51 & 0.07 & PRT & -0.02 & 0.05 & -0.54 & 0.07 \\
\hline GBR & -0.02 & 0.05 & -0.51 & 0.07 & SEN & 0.00 & 0.05 & -0.53 & 0.07 \\
\hline GHA & -0.05 & 0.05 & -0.48 & 0.07 & SGP & -0.02 & 0.05 & -0.52 & 0.07 \\
\hline GRC & -0.02 & 0.05 & -0.51 & 0.07 & SWE & -0.02 & 0.05 & -0.53 & 0.07 \\
\hline HKG & -0.02 & 0.05 & -0.37 & 0.07 & THA & -0.01 & 0.05 & -0.51 & 0.07 \\
\hline IDN & -0.02 & 0.05 & -0.51 & 0.07 & TUN & -0.02 & 0.05 & -0.51 & 0.07 \\
\hline IND & 0.01 & 0.05 & -0.54 & 0.07 & TUR & -0.03 & 0.05 & -0.50 & 0.07 \\
\hline IRL & -0.02 & 0.05 & -0.54 & 0.07 & TWN & -0.02 & 0.05 & -0.49 & 0.07 \\
\hline ISR & -0.02 & 0.05 & -0.52 & 0.07 & URY & -0.02 & 0.05 & -0.50 & 0.07 \\
\hline ITA & -0.02 & 0.05 & -0.51 & 0.07 & USA & -0.02 & 0.05 & -0.53 & 0.07 \\
\hline JAM & -0.02 & 0.05 & -0.51 & 0.07 & VEN & 0.00 & 0.05 & -0.53 & 0.07 \\
\hline JOR & -0.04 & 0.05 & -0.49 & 0.07 & ZAF & -0.02 & 0.05 & -0.51 & 0.07 \\
\hline JPN & -0.02 & 0.05 & -0.52 & 0.07 & ZMB & -0.02 & 0.05 & -0.51 & 0.07 \\
\hline KEN & -0.15 & 0.05 & -0.38 & 0.07 & ZWE & 0.03 & 0.05 & -0.55 & 0.07 \\
\hline
\end{tabular}

This table reports the estimated coefficients for $\lambda_{2}$ and $\lambda_{3}$, for the specification in Column 3 of Table 4 , leaving out one country (the one indicated for each set of coefficients) at at time. 
Table 7: Estimation Results Excluding Hong Kong And KenYA

\begin{tabular}{|c|c|c|c|c|c|c|c|c|}
\hline & $(1)$ & (2) & (3) & $(4)$ & (5) & (6) & (7) & (8) \\
\hline & \multicolumn{8}{|c|}{ Change in Log-Employment } \\
\hline $\operatorname{Gap}\left(\lambda_{1}\right)$ & $\begin{array}{c}0.615 \\
(0.009)^{* * *}\end{array}$ & $\begin{array}{c}0.620 \\
(0.009)^{* * * *}\end{array}$ & $\begin{array}{c}0.649 \\
(0.012)^{* * * *}\end{array}$ & $\begin{array}{c}0.652 \\
(0.012)^{* * *}\end{array}$ & & & & \\
\hline $\operatorname{Gap} \times \operatorname{JS}\left(\lambda_{2}\right)$ & & $\begin{array}{c}-0.105 \\
(0.039)^{* * *}\end{array}$ & $\begin{array}{c}-0.156 \\
(0.051)^{* * *}\end{array}$ & $\begin{array}{c}-0.163 \\
(0.051)^{* * *}\end{array}$ & $\begin{array}{c}-0.204 \\
(0.042)^{* * *}\end{array}$ & $\begin{array}{c}-0.171 \\
(0.052)^{* * *}\end{array}$ & $\begin{array}{c}-0.183 \\
(0.052)^{* * *}\end{array}$ & \\
\hline $\operatorname{Gap} \times \mathrm{JS} \times \operatorname{DSRL}\left(\lambda_{3}\right)$ & & & $\begin{array}{c}-0.231 \\
(0.062)^{* * *}\end{array}$ & & & $\begin{array}{l}-0.062 \\
(0.072)\end{array}$ & & \\
\hline Gap $\times$ JS $\times$ DHGE $\left(\lambda_{3}\right)$ & & & & $\begin{array}{c}-0.227 \\
(0.070)^{* * *}\end{array}$ & & & $\begin{array}{l}-0.071 \\
(0.072)\end{array}$ & \\
\hline $\operatorname{Gap} \times \operatorname{HP}\left(\lambda_{2}\right)$ & & & & & & & & $\begin{array}{c}-0.021 \\
(0.007)^{* * *}\end{array}$ \\
\hline \multicolumn{9}{|l|}{ Controls } \\
\hline Gap $\times$ Dummy High RL & & & $\begin{array}{c}-0.121 \\
(0.015)^{* * * *}\end{array}$ & & & $\begin{array}{c}0.065 \\
(0.023)^{* * *}\end{array}$ & & \\
\hline Gap $\times$ Dummy High GE & & & & $\begin{array}{c}-0.136 \\
(0.015)^{* * *}\end{array}$ & & & $\begin{array}{c}0.023 \\
(0.024)\end{array}$ & \\
\hline Observations & 20,881 & 20,881 & 20,881 & 20,881 & 20,881 & 20,881 & 20,881 & 12,003 \\
\hline R-squared & 0.61 & 0.61 & 0.61 & 0.61 & 0.62 & 0.62 & 0.62 & 0.62 \\
\hline Gap-Income Interaction & No & No & No & No & Yes & Yes & Yes & Yes \\
\hline Gap-Sector Interaction & No & No & No & No & Yes & Yes & Yes & Yes \\
\hline
\end{tabular}

* significant at 10\%; ** significant at 5\%; *** significant at 1\%. Robust standard errors in parentheses. JS and HP stand for the Djankov et al. (2003) and Heckman and Pages (2000) job security measures, respectively. DSRL and DHGE stand for high (above Greece, see main text) Rule of Law and Government Efficiency dummies, respectively, using the Kaufmann et al. (1999) indices. Each regression has country-year fixed effects. Gaps are estimated using a constant $\phi=0.42$. Sample excludes the upper and lower $1 \%$ of $\Delta e$ and of the estimated values of Gap. 
Table 8: IV Estimation

\begin{tabular}{|c|c|c|}
\hline \multirow[b]{2}{*}{ Estimation Method } & \multicolumn{2}{|c|}{ Average speed of adjustment } \\
\hline & Point Estimate & Robust Standard Error \\
\hline Baseline Model (Column 1 in Table 4 & 0.600 & 0.009 \\
\hline Gap instrumented with wage data & 0.570 & 0.065 \\
\hline Standard dynamic panel formulation & 0.543 & 0.078 \\
\hline
\end{tabular}

See section 3.2.3 for details. 
Table 9: Estimating Country-Specific Speeds of Adjustment

\begin{tabular}{|c|c|c|c|c|c|c|c|c|c|}
\hline Country & $\lambda_{c, 1}$ & St. Dev. & $\lambda_{c, 2}$ & St. Dev. & Country & $\lambda_{c, 1}$ & St. Dev. & $\lambda_{c, 2}$ & St. Dev. \\
\hline ARG & 0.380 & 0.060 & 0.364 & 0.071 & KOR & 0.719 & 0.028 & 0.696 & 0.052 \\
\hline AUS & 0.558 & 0.048 & 0.537 & 0.063 & LKA & 0.744 & 0.041 & 0.729 & 0.056 \\
\hline AUT & 0.521 & 0.040 & 0.504 & 0.056 & MAR & 0.572 & 0.060 & 0.569 & 0.071 \\
\hline BEL & 0.160 & 0.046 & 0.158 & 0.062 & MDG & 0.688 & 0.067 & 0.666 & 0.075 \\
\hline BFA & 0.327 & 0.066 & 0.309 & 0.076 & MEX & 0.467 & 0.042 & 0.451 & 0.058 \\
\hline BOL & 0.562 & 0.049 & 0.545 & 0.064 & MOZ & 0.414 & 0.111 & 0.370 & 0.122 \\
\hline BRA & 0.385 & 0.067 & 0.346 & 0.078 & MWI & 0.499 & 0.095 & 0.437 & 0.094 \\
\hline CAN & 0.565 & 0.038 & 0.547 & 0.055 & NYS & 0.750 & 0.032 & 0.723 & 0.053 \\
\hline CHL & 0.631 & 0.045 & 0.618 & 0.061 & NGA & 0.782 & 0.094 & 0.754 & 0.102 \\
\hline $\mathrm{COL}$ & 0.624 & 0.030 & 0.591 & 0.052 & NLD & 0.467 & 0.060 & 0.414 & 0.073 \\
\hline DEU & 0.463 & 0.048 & 0.458 & 0.062 & NOR & 0.472 & 0.037 & 0.468 & 0.054 \\
\hline DNK & 0.500 & 0.058 & 0.488 & 0.070 & NZL & 0.483 & 0.065 & 0.443 & 0.076 \\
\hline ECU & 0.645 & 0.044 & 0.624 & 0.059 & PAK & 0.771 & 0.054 & 0.740 & 0.069 \\
\hline EGY & 0.694 & 0.052 & 0.671 & 0.065 & PAN & 0.575 & 0.049 & 0.561 & 0.064 \\
\hline ESP & 0.488 & 0.033 & 0.469 & 0.052 & PER & 0.379 & 0.038 & 0.376 & 0.056 \\
\hline FIN & 0.445 & 0.032 & 0.428 & 0.051 & PHL & 0.664 & 0.036 & 0.652 & 0.055 \\
\hline FRA & 0.292 & 0.032 & 0.278 & 0.052 & PRT & 0.369 & 0.029 & 0.362 & 0.050 \\
\hline GBR & 0.577 & 0.037 & 0.565 & 0.054 & SEN & 0.716 & 0.080 & 0.707 & 0.090 \\
\hline GHA & 0.502 & 0.064 & 0.498 & 0.075 & SGP & 0.631 & 0.039 & 0.605 & 0.057 \\
\hline GRC & 0.552 & 0.032 & 0.536 & 0.052 & SWE & 0.578 & 0.037 & 0.555 & 0.054 \\
\hline HKG & 0.837 & 0.029 & 0.821 & 0.050 & THA & 0.490 & 0.143 & 0.450 & 0.142 \\
\hline IDN & 0.676 & 0.046 & 0.645 & 0.061 & TUN & 0.633 & 0.099 & 0.605 & 0.099 \\
\hline IND & 0.746 & 0.051 & 0.736 & 0.067 & TUR & 0.506 & 0.031 & 0.475 & 0.051 \\
\hline IRL & 0.516 & 0.031 & 0.488 & 0.051 & TWN & 0.406 & 0.037 & 0.379 & 0.056 \\
\hline ISR & 0.606 & 0.040 & 0.592 & 0.057 & URY & 0.584 & 0.034 & 0.575 & 0.053 \\
\hline ITA & 0.364 & 0.047 & 0.341 & 0.062 & USA & 0.544 & 0.040 & 0.542 & 0.056 \\
\hline JAM & 0.563 & 0.411 & 0.510 & 0.364 & VEN & 0.519 & 0.037 & 0.515 & 0.056 \\
\hline JOR & 0.697 & 0.041 & 0.681 & 0.057 & ZAF & 0.581 & 0.044 & 0.548 & 0.059 \\
\hline JPN & 0.470 & 0.035 & 0.463 & 0.054 & ZMB & 0.482 & 0.095 & 0.457 & 0.106 \\
\hline KEN & 0.224 & 0.038 & 0.201 & 0.055 & ZWE & 0.774 & 0.051 & 0.749 & 0.064 \\
\hline 1st quintile & 0.346 & & 0.325 & & & & & & \\
\hline 2nd quintile & 0.482 & & 0.457 & & & & & & \\
\hline 3rd quintile & 0.546 & & 0.527 & & & & & & \\
\hline 4th quintile & 0.619 & & 0.600 & & & & & & \\
\hline 5th quintile & 0.743 & & 0.723 & & & & & & \\
\hline
\end{tabular}

This table reports estimated coefficients for $\lambda$ at the country level. A common value of $\phi=0.40$ is used throughout. $\lambda_{c, 2}$ includes sectoral controls, while $\lambda_{c, 1}$ does not. 
Table 10: Productivity Growth And Speed of Adjustment I

\begin{tabular}{cc}
\hline \hline Change in $\lambda_{c}$-Quintile & Change in Annual Growth Rate \\
\hline 1st to 2nd & $0.88 \%$ \\
2nd to 3rd & $0.29 \%$ \\
3rd to 4th & $0.23 \%$ \\
4th to 5th & $0.28 \%$ \\
\hline 1st to 5th & $1.68 \%$ \\
\hline
\end{tabular}

Reported: change in annual growth rates associated with moving from the average adjustment speed of one quintile to the next. Quintiles for $\lambda_{c}$ from Table 9, column with sectoral controls. Calculation based on model described in Section 4 (see equation (19)). Parameter values: $\gamma=5 / 6), g_{Y, 1}=0.007, \sigma=0.27 \alpha=2 / 3$, and $\delta=0.06$. 


\section{Table 11: Productivity Growth And SpeEd of Adjustment II}

\begin{tabular}{lcccccc}
\hline \hline & $(1)$ & $(2)$ & $(3)$ & $(4)$ & $(5)$ & $(6)$ \\
& \multicolumn{7}{c}{ Annual Average Change in TFP 1980-1990 } \\
\hline Speed of adjustment: & 0.040 & 0.031 & 0.053 & 0.026 & 0.026 & 0.046 \\
& $(0.018)^{* *}$ & $(0.019)^{*}$ & $(0.018)^{* * *}$ & $(0.019)$ & $(0.019)$ & $(0.019)^{* *}$ \\
& & & & & & \\
Constant: & -0.016 & -0.013 & -0.016 & -0.012 & -0.012 & -0.014 \\
& $(0.010)$ & $(0.010)$ & $(0.009)^{*}$ & $(0.011)$ & $(0.010)$ & $(0.009)$ \\
& & & & & & \\
\hline & 42 & 42 & 42 & 42 & 42 & 42 \\
Observations & 0.108 & 0.066 & 0.294 & 0.043 & 0.041 & 0.230 \\
R-squared & No & No & Yes & No & No & Yes \\
Income Fixed Effects & WLS & WLS & WLS & OLS & OLS & OLS \\
Estimation via & & & & & & \\
\hline \hline
\end{tabular}

* significant at $10 \%$; ** significant at 5\%; *** significant at 1\%. Robust standard errors in parentheses. Samplesize determined by availability of TFP data. TFP growth at the country level calculated following Mankiw (1995): TFP growth $=$ Per-capita GDP growth -0.3 Per-capita capital growth -0.5 Avge. Schooling growth. The data comes from World Penn Tables 5.6 and Barro and Lee (1996). WLS refers to weighted least squares, with weights inversely proportional to the standard deviation of estimated $\lambda_{c}$ 's. OLS refers to ordinary least squares. 